PERENCANAAN SISTEM PENYEGARAN ARA UNTUK RUANG KELAS FAKULTAS TEKNIK UTA'45 JAKARTA

(Audri Deacy Cappenberg)

DESAIN SLIDE ADJUSTER KURSI TRUK MENGGUNAKAN METODE TRIZ

(Choirul Anwar ${ }^{1}$, Budhi M. S., Susanto $S^{2}$ )

PENGARUH PENAMBAHAN OKSIGENAT PADA SOLAR TERHADAP EMISI GAS BUANG MESIN DIESEL

(Yos Nofendri)

KARAKTERISTIK SIFAT MEKANIS ANTARA TIGA PRODUK MANUFAKTUR ELEKTRODA E6013

(Basori $^{1}$, Ferry Budhi Susetyo ${ }^{2}$ )

PROTOTYPE ALAT BEJANA PEMBAKARAN

(Sugeng Priyanto)
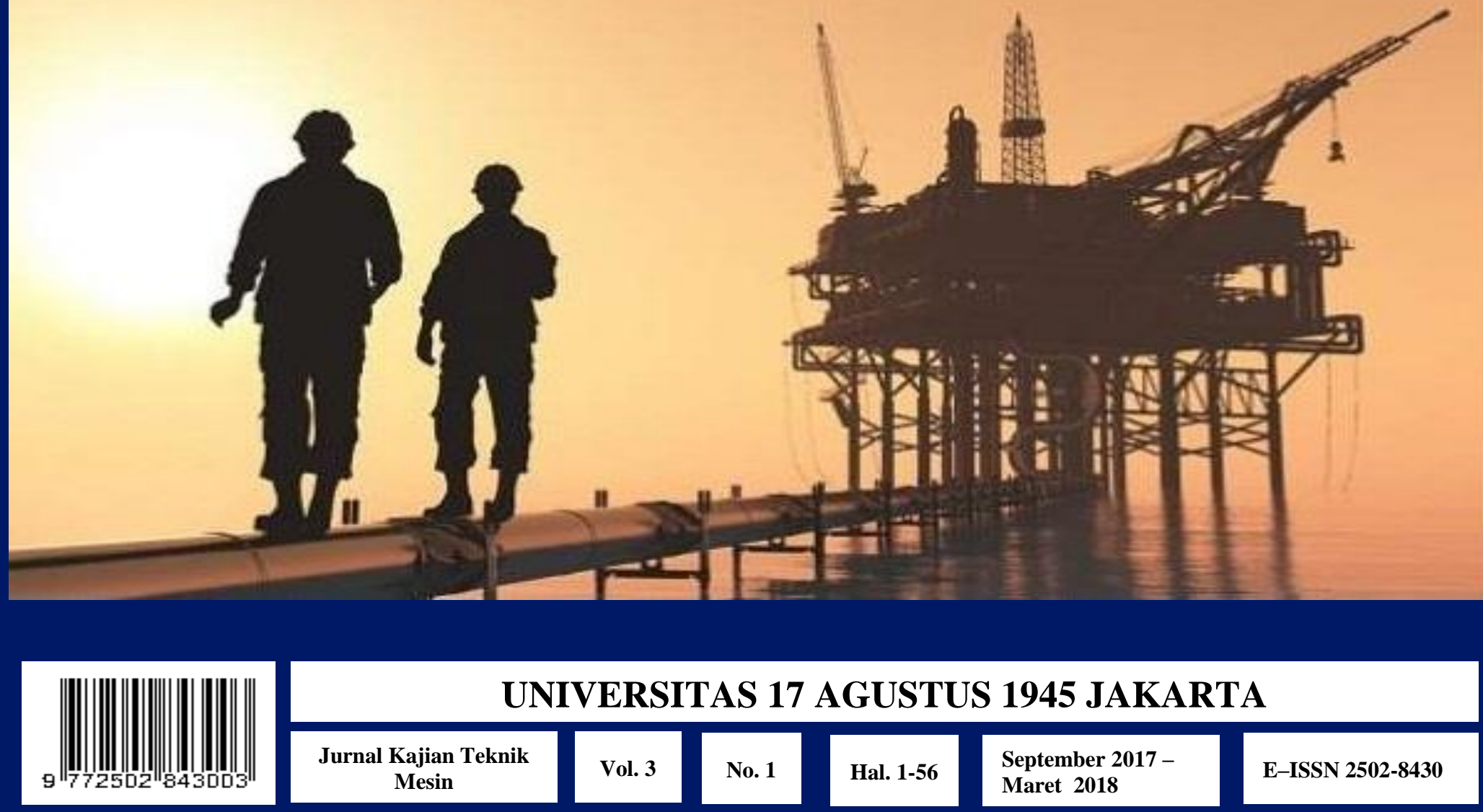

UNIVERSITAS 17 AGUSTUS 1945 JAKARTA

Mesin

Vol. 3
Hal. 1-56
September 2017 -

Maret 2018 


\title{
JURNAL KAJIAN TEKNIK MESIN
}

\section{Susunan Team Redaksi Jurnal Kajian Teknik Mesin}

\section{$\underline{\text { Pemimpin redaksi }}$}

Andi Saidah

\section{Dewan Redaksi}

Sri Endah Susilowati

Harini

Audri Deacy Cappenberg

Yos Nofendri

Didit Sumardiyanto

\section{$\underline{\text { Redaksi Pelaksana }}$}

M. Fajri Hidayat

\section{$\underline{\text { English Editor }}$}

English Center UTA`45 Jakarta

\section{Staf Sekretariat}

Dani

Suyatno

\author{
Alamat Redaksi \\ Program Studi Teknik Mesin universitas 17 Agustus 1945 Jakarta \\ J1.Sunter Permai Raya, Jakarta Utara, 14350, Indonesia \\ Telp: 021-647156666-64717302, Fax:021-64717301
}




\section{JURNAL KAJIAN TEKNIK MESIN}

\section{DAFTAR ISI}

OPTIMASI DESAIN PADA DINDING FURNACE DENGAN

TEMPERATUR KERJA $1000^{\circ} \mathrm{C}$

(Khoirudin ${ }^{1}$, La Ode Mohammad Firman ${ }^{2}$ )

PERENCANAAN SISTEM PENYEGARAN UDARA UNTUK RUANG

KELAS FAKULTAS TEKNIK UTA'45 JAKARTA

(Audri Deacy Cappenberg)

DESAIN SLIDE ADJUSTER KURSI TRUK MENGGUNAKAN

METODE TRIZ

(Choirul Anwar ${ }^{1}$, Budhi M. S., Susanto S ${ }^{2}$ )

PENGARUH PENAMBAHAN OKSIGENAT PADA SOLAR

TERHADAP EMISI GAS BUANG MESIN DIESEL

(Yos Nofendri)

KARAKTERISTIK SIFAT MEKANIS ANTARA TIGA PRODUK MANUFAKTUR ELEKTRODA E6013

(Basori $^{1}$, Ferry Budhi Susetyo ${ }^{2}$ )

(Sugeng Priyanto) 


\title{
KARAKTERISTIK SIFAT MEKANIS ANTARA TIGA PRODUK MANUFAKTUR
} ELEKTRODA E6013

\author{
${ }^{1)}$ Basori, dan ${ }^{2)}$ Ferry Budhi Susetyo \\ ${ }^{1)}$ Teknik Mesin, Fakultas Teknik dan Sains, Universitas Nasional \\ ${ }^{2)}$ Teknologi Mesin, Fakultas Teknik, Universitas Negeri Jakarta \\ e-mail : ory_banjarn@yahoo.com
}

\begin{abstract}
ABSTRAK
Jenis elektroda yang digunakan dalam proses SMAW memiliki jenis yang banyak, seperti E 6010, E 6011, E 6012, E 6013, E 6020, E6027. Dalam hal ini jenis E 6013 adalah yang paling banyak digunakan. Tentunya jenis E 6013 di produksi oleh manufaktur yang berbeda-beda pula. Dari penelurusan peneliti jenis ini memiliki harga yang berbeda-beda sesuai dengan perusahaan yang menjualnya. Untuk itu peneliti tertarik untuk membandingkan ketiga hasil produksi manufaktur untuk jenis E 6013 ditinjau dari sifat mekaniknya. Pembuatan spesimen las elektroda potong material yang akan digunakan. kemudian amplas material yang sudah dipotong agar tidak ada sisa potongan yang masih menempel. Langkah selanjutnya lakukan proses pengelasan dengan tiga jenis elekroda E6013. Pengelasan dilakukan hingga mencapai ketebalan lapisan $10 \mathrm{~mm}$ lapis, kemudian plat dasar dibuang dan sisisakan deposit lasnya saja Nilai kekuatan impak dan kekerasan permukaan hasilnya berbanding terbalik. Untuk pengujian impak, spesimen sampel elektroda E1 memiliki nilai kekuatan impak tertinggi dan spesimen sampel elektroda E3 memiliki nilai kekuatan impak terendah. Sedangkan pada pengujian kekerasan spesimen sampel elektroda E3 memiliki nilai kekerasan tertinggi dan spesimen sampel elektroda E1 memiliki nilai kekerasan terendah. Hal ini dapat membuktikan bahwa semakin benda itu keras maka semakin getas pula benda tersebut.
\end{abstract}

Kata kunci: E6013, SMAW, impak dan Kekerasan

\begin{abstract}
The type of electrode used in the SMAW process has many types, such as E 6010, E 6011, E 6012, E 6013, E 6020, E6027. In this case the type E 6013 is the most widely used. Certainly the type E 6013 is produced by different manufacturers as well. From penelurusan researchers of this type have different prices in accordance with companies that sell it. For that reason researchers are interested to compare the three manufacturing outputs for the type E 6013 in terms of its mechanical properties. Making a specimen welding electrode cut material to be used. then sandpaper the material that has been cut so that no remaining pieces are still attached. The next step to do the welding process with three types of E6013 elekroda. The welding is carried out until it reaches the layer layer $10 \mathrm{~mm}$ thickness, then the bottom plate is discarded and the weld deposit deposits only The impact strength and surface hardness value are inversely proportional. For the impact test, the E1 electrode sample specimen has the highest impact strength value and the E3 electrode sample specimen has the lowest impact strength value. While on the hardness test specimen E3 electrode sample has the highest hardness value and sample specimen El electrode has the lowest hardness value. This can prove that the harder the object is the more brittle the object.
\end{abstract}

Keyword : E6013, SMAW, impact test, hardness

\section{PENDAHULUAN}

Perkembangan zaman yang semakin pesat sangat berpengaruh pada perkembangan dunia teknologi. Dimana teknologi dibutuhkan sebagai penunjang dalam pemenuhan kebutuhan hidup manusia. Teknologi pengelasan dalam dunia konstruksi merupakan salah satu yang ikut berkembang. (Wiryosumarto, 2000)

Pengelasan adalah suatu proses penyambungan logam dimana logam menjadi satu akibat panas dengan atau tanpa tekanan, atau dapat didefinisikan sebagai akibat dari metalurgi yang ditimbulkan oleh gaya tarik menarik antara atom. (Amstead, 1997). Pe gelasan menurut panas tenaga listrik dibagi menjadi: SMAW, SAW, ESW, Stud Welding, ERW, dan EBW. 
(Widharto, 2009) Dalam dunia pengelasan, jenis pengelasan yang sering digunakan adalah metode busur nyala logam terlindung atau biasa disebut Shielded Metal Arc Welding (SMAW). Metode SMAW dianggap lebih praktis dan efisien dalam pengerjaan yang dapat dilakukan di seluruh posisi. (Wiryosumarto, 2000)

Dikenal tiga jenis elektroda logam yaitu, elektroda polos, elektroda fluks dan berlapis tebal. (Amstead, 1997) Jenis elektroda yang digunakan dalam proses SMAW adalah jenis elektroda fluks. Elektroda fluks ini distandarisasi dalam AWS seperti E 6010, E 6011, E 6012, E 6013, E 6020, E 6027. (Wiryosumarto, 2000)

Namun dalam penelusuran peneliti ke bengkel-bengkel las yang ada, jenis E 6013 adalah yang paling banyak digunakan. Kemudian yang menarik, pada tipa-tiap bengkel las menggunakan merek yang berbeda-beda. Dari penelurusan peneliti, merek yang berbeda untuk jenis ini memiliki harga yang berbeda-beda pula sesuai dengan perusahaan yang meproduksinya. Untuk itu peneliti tertarik untuk membandingkan ketiga hasil produksi manufaktur untuk jenis E 6013 ditinjau dari sifat mekaniknya yaitu untuk sifat kekerasan dan sifat keuletannya. (Sunari, 2007)

\section{METODOLOGI PENELITIAN}

Alur yang dilakukan adalah sebagai berikut :

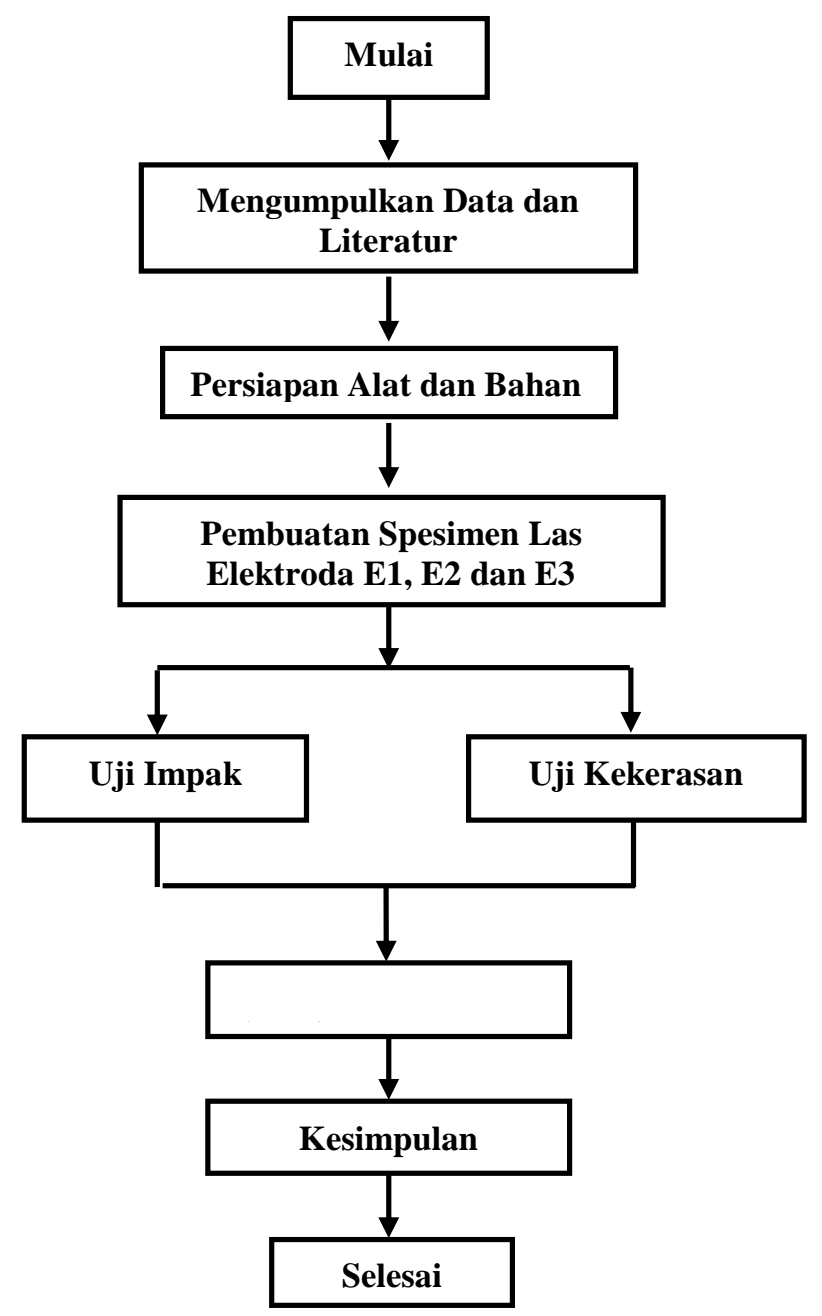


Gambar 2.1. Alur Proses Penelitian

Penjelasan alur penelitian sebagai berikut :

A. Mengumpulkan data dan literatur

Mengumpulkan data dan literatur yaitu dengan mengumpulkan buku-buku teknik pengelasan, dan pengamatan elektroda yang sering digunakan.

B. Persiapan bahan dan alat

Peralatan dan bahan yang digunakan dalam penelitian ini adalah, sebagai berikut :

- Baja Karbon Rendah (100 mm x 50 mm x 3 mm)

- Elektroda (E1, E2, E3)

- Mesin Frais

- Mesin Grinding

- Kikir

- Palu Terak

- Perangkat Las SMAW

- Sikat Kawat

- Amplas

- Gergaji

C. Pembuatan Spesimen Las Elektroda E1, E2, dan E3.

Pembuatan spesimen las elektroda potong material yang akan digunakan. kemudian amplas material yang sudah dipotong agar tidak ada sisa potongan yang masih menempel. Langkah selanjutnya lakukan proses pengelasan. Langkah-langkah yang dilakukan dalam proses pengelasan adalah :

1. Mempersiapkan perangkat las proses SMAW.

2. Mempersiapkan benda kerja yang akan dilas pada meja las.

3. Posisi pengelasan dengan menggunakan posisi pengelasan mendatar atau bawah tangan (1G)

4. Mempersiapkan tiga jenis elekroda E6013.

5. Atur arus las busur listrik sesuai kebutuhan dan selanjutnya mulai melakukan proses pengelasan.

6. Pengelasan dilakukan hingga mencapai ketebalan lapisan $10 \mathrm{~mm}$.

7. kemudian plat dasar dibuang dan sisakan deposit lasnya saja

D. Uji Impak. (Koswara, 1999)

Langkah-langkah yang dilakukan dalam pengujian Impak adalah :

1. Menyiapkan alat dan bahan.

2. Membuat spesimen sesuai standar pengujian yaitu ASTM E 23

3. Mengukur spesimen yang akan diujikan.

4. Memasang spesimen pada penahan alat uji impak, setelah mengkalibrasi alat uji impak.

5. Mengangkat pendulum dan melepaskan tuas.

6. Hasil dan analisis hasil pengujiannya.

E. Uji Kekerasan Vickers. (Koswara, 1999)

Langkah-langkah yang dilakukan dalam pengujian kekerasan adalah:

1. Menyiapkan alat dan bahan.

2. Memoles bagian yang akan diuji kekerasan.

3. Memasang spesimen pada penahan alat uji kekerasan, setelah mengkalibrasi alat uji kekerasan. 
4. Lakukan pembebanan dengan cara penekanan menggunakan indetor. Tekan spesimen hingga muncul hasil dari uji kekerasan.

5. Hasil dan analisis hasil pengujiannya.

G. Analisis Data

Analisis data untuk mengetahui hasil pengujian yang terbaik dari tiga jenis elektroda yang berbeda.

H. Kesimpulan

Kesimpulan dari penelitian ini adalah berdasarkan hasil dari uji impak, dan uji kekerasan.

3. ANALISA HASIL

\subsection{Analisa Hasil Pengujian Keras}

Jumlah spesimen yang diuji impak dalam penelitian ini berjumlah sembilan spesimen. sembilan spesimen ini terbagi tiga, yaitu : spesimen dari sampel elektroda E1 sebanyak tiga buah, dari sampel elektroda E2 sebanyak tiga buah, dan dari sampel elektroda E3 sebanyak tiga buah yang mengacu pada standar ASTM E 23. Adapun hasil pengujian kekuatan impak seperti pada tabel di bawah ini :

Tabel 3.1. Nilai Kekuatan Impak

\begin{tabular}{|c|c|c|c|c|}
\hline No & $\begin{array}{c}\text { Sampel } \\
\text { Elektroda }\end{array}$ & Spesimen & $\begin{array}{c}\text { Kekuatan } \\
\text { Impak } \\
(\text { Joule/cm²) }\end{array}$ & $\begin{array}{c}\text { Rata-rata } \\
\text { (Joule/cm²) }\end{array}$ \\
\hline \multirow{3}{*}{1} & \multirow{3}{*}{ E1 } & E1a & 239,55 & \multirow{3}{*}{277.72} \\
\hline & & E1b & 297,31 & \\
\hline & & E1c & 296,29 & \\
\hline \multirow{3}{*}{2} & \multirow{3}{*}{ E2 } & $\mathrm{E} 2 \mathrm{a}$ & 275,82 & \multirow{3}{*}{264.89} \\
\hline & & $\mathrm{E} 2 \mathrm{~b}$ & 284,49 & \\
\hline & & $\mathrm{E} 2 \mathrm{c}$ & 234,36 & \\
\hline \multirow{3}{*}{3} & \multirow{3}{*}{ E3 } & E3a & 172,19 & \multirow{3}{*}{162.51} \\
\hline & & E3b & 131,20 & \\
\hline & & E3c & 184,15 & \\
\hline
\end{tabular}

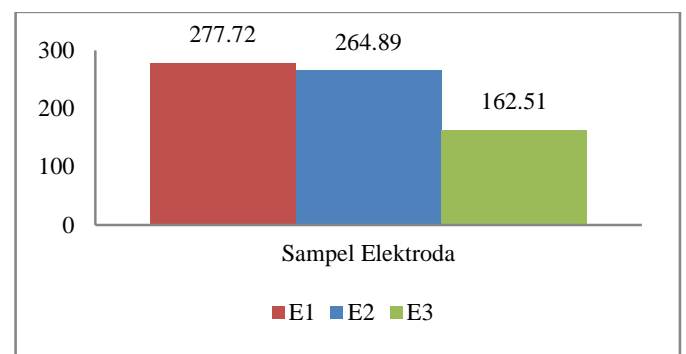

Gambar 3.1. Grafik Rata - Rata Pengujian Impak

Dari grafik di atas bisa disimpulkan bahwa sampel elektroda E1 lah yang memiliki kekuatan impak paling tinggi. Dengan kata lain, spesimen yang dibuat menggunakan sampel elektroda E1-lah yang memiliki penyerapan energi paling besar dan dapat dikatakan paling ulet dibandingkan oleh spesimen sampel elektroda E2 dan E3. Perbedaan antara rata-rata kekuatan impak atara sampel E1 dan E2 tidak terlalu jauh, tetapi untuk elektroda E3 terlihat cukup jauh dibawah E1 dan E2.

\subsection{Analisa Hasil Pengujian Keras}

\section{3}

Jumlah spesimen yang diuji kekerasan dalam penelitian ini berjumlah tiga spesimen (E1, E2 dan E3) dan menggunakan sembilan titik penekanan pada bagian permukaan tiap 
spesimen. Beban yang digunakan dalam pengujian ini adalah 10Kgf. Adapun hasil pengujian kekuatan tarik seperti pada tabel di bawah ini :

Tabel 3-2. Nilai Kekerasan

\begin{tabular}{|c|c|c|c|c|}
\hline No & $\begin{array}{l}\text { Sampel } \\
\text { Elektroda }\end{array}$ & Spesimen & $\begin{array}{c}\text { Nilai } \\
\text { Kekerasan } \\
\text { (VHN) }\end{array}$ & $\begin{array}{c}\text { Rata-rata } \\
\text { (VHN) }\end{array}$ \\
\hline \multirow{9}{*}{1} & \multirow{9}{*}{ E1 } & E1a & 125.05 & \multirow{9}{*}{118.93} \\
\hline & & E1b & 123.69 & \\
\hline & & E1c & 120.78 & \\
\hline & & $\overline{\text { E1d }}$ & 120.10 & \\
\hline & & E1e & 118.98 & \\
\hline & & E1f & 117.63 & \\
\hline & & E1g & 116.34 & \\
\hline & & E1h & 114.61 & \\
\hline & & E1i & 113.20 & \\
\hline \multirow{9}{*}{2} & \multirow{9}{*}{ E2 } & E2a & 131.04 & \multirow{9}{*}{135.47} \\
\hline & & E2b & 129.96 & \\
\hline & & E2c & 133.54 & \\
\hline & & E2d & 138.63 & \\
\hline & & E2e & 148.41 & \\
\hline & & E2f & 128.53 & \\
\hline & & E2g & 132.23 & \\
\hline & & E2h & 143.21 & \\
\hline & & E2i & 133.65 & \\
\hline \multirow{9}{*}{3} & \multirow{9}{*}{ E3 } & E3a & 165.40 & \multirow{9}{*}{162.89} \\
\hline & & E3b & 169.32 & \\
\hline & & E3c & 171.49 & \\
\hline & & E3d & 153.98 & \\
\hline & & E3e & 151.95 & \\
\hline & & E3f & 160.62 & \\
\hline & & E3g & 170.92 & \\
\hline & & E3h & 166.10 & \\
\hline & & E3i & 156.22 & \\
\hline
\end{tabular}

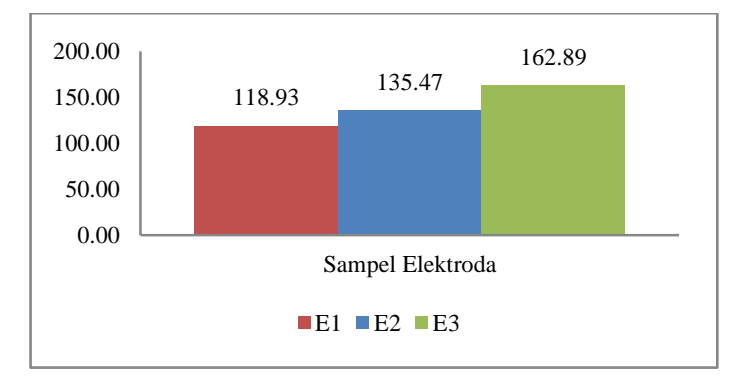

Gambar 3.2. Grafik Rata - Rata Pengujian Kekerasan

Dari grafik di atas bisa disimpulkan bahwa sampel elektroda E3 lah yang memiliki nilai kekerasan paling tinggi. Perbedaan antara rata-rata kekuatan keras atara sampel E1, E2 dan E3 memang tidak terlalu jauh. Tetapi terbukti bahwa ada perbedaan tingkat kekerasan permukaan Weld Metal pada tiap spesimen. Berbanding terbalik dengan pengujian impak, dimana E1 yang paling tinggi tingkat penyerapan kekuatan impaknya dan E3 yang terendah. Tetapi, di tingkat kekerasan permukaan, E3 lah yang paling tinggi dan E1 yang paling rendah.

\section{KESIMPULAN DAN SARAN}

\section{A. Kesimpulan}

Dari hasil yang didapat didapatkan hasil kesimpulan sebagai berikut: 
1. Kekuatan impak yang nilainya paling tinggi didapat oleh pengujian impak pada spesimen sampel elektroda E1 yang memiliki nilai kekuatan impak sebesar 277,72 joule $/ \mathrm{cm}^{2}$. sedangkan kekuatan impak yang nilainya paling rendah didapat oleh pengujian impak pada spesimen sampel elektroda E3 yang memiliki nilai kekuatan impak sebesar 162,51 joule/ $\mathrm{cm}^{2}$.

2. Nilai kekerasan yang paling tinggi didapat oleh pengujian kekerasan pada spesimen sampel elektroda E3 yang memiliki nilai kekerasan sebesar 162,89 VHN. Sedangkan nilai kekerasan yang paling rendah didapat oleh pengujian kekerasan pada spesimen sampel elektroda E1 yang memiliki nilai kekerasan sebesar 118,93 VHN.

3. Nilai kekuatan impak dan kekerasan permukaan hasilnya berbanding terbalik. Untuk pengujian impak, spesimen sampel elektroda E1 memiliki nilai kekuatan impak tertinggi dan spesimen sampel elektroda E3 memiliki nilai kekuatan impak terendah. Sedangkan pada pengujian kekerasan spesimen sampel elektroda E3 memiliki nilai kekerasan tertinggi dan spesimen sampel elektroda E1 memiliki nilai kekerasan terendah. Hal ini dapat membuktikan bahwa semakin benda itu keras maka semakin getas pula benda tersebut.

\section{B. Saran}

1. Perlu dilakukan penelitian lanjutan untuk mengetahui struktur mikro yang terdapat pada Weld Metal dengan alat struktur mikro.

2. Perlu dilakukan penelitian lanjutan untuk melakukan normalizing terlebih dahulu sebelum dilakukan pengujian sifat mekanik.

\section{DAFTAR PUSTAKA}

Amstead, B.H., dkk. (1997). Teknologi Mekanik. Jakarta: Erlangga.

Djaprie, Sriati. (1992). Metalurgi Mekanis. Jilid 1 Erlangga , Jakarta.

Koswara, Engkos. (1999). Pengujian Logam. Humaniora Utama Press Bandung, Bandung.

Sunari. (2007). Teknik Pengelasan Logam. Ganeca Exact. Bandung.

Widharto, Sri. (2009). Petunjuk Kerja Las. Pradnya Paramita. Jakarta.

Wiryosumarto, H. dan Okumura, T. (2000). Teknologi Pengelasan Logam, Pradnya Paramita, Jakarta. 